\title{
Ageing and endurance training effects on quantity and quality of pulmonary vascular bed in healthy men
}

\author{
Ghanima Al Dandachi ${ }^{1}$, Cécile Londner ${ }^{1}$, Aurore Caumont-Prim ${ }^{2}$, Laurent Plantier ${ }^{1,4}$, Brigitte Chevalier-Bidaud ${ }^{1,2}$, \\ Jean-François Toussaint ${ }^{3,4}$, François-Denis Desgorces ${ }^{3,4}$ and Christophe Delclaux $1,4,5,6,7^{*}$
}

\begin{abstract}
It has recently been demonstrated that in healthy individuals, peak oxygen consumption is associated with a greater pulmonary capillary blood volume and a more distensible pulmonary circulation. Our cross-sectional study suggests that, in healthy men aged 20 to 60 years $(n=63)$, endurance sport practice (vigorous-intensity domain of the International Physical Activity Questionnaire) is associated with better quantity (pulmonary capillary blood volume) and quality (slope of increase in lung diffusion for carbon monoxide on exercise) of the pulmonary vascular bed, partly counterbalancing the deleterious effects of ageing, which remains to be demonstrated in a prospective longitudinal design.
\end{abstract}

Keywords: Physical activity, Exercise, Capillary blood volume, Lung diffusion

\section{Findings}

\section{Background}

Pulmonary vascular response to exercise varies considerably from one individual to another [1], which is partly explained by the natural distensibility of the pulmonary circulation [2]. Capillary resistance significantly contributes to changes in pulmonary vascular resistance during exercise. Capillary blood volume available for gas exchange (VC) can be estimated from lung diffusing capacity measurements using both carbon monoxide $(\mathrm{CO})$ and nitric oxide (NO) as tracer gases [3]. Lalande et al. recently demonstrated that in healthy individuals, peak oxygen consumption $\left(\dot{V} \mathrm{O}_{2, \text { peak }}\right)$ on exercise is associated with a greater pulmonary capillary blood volume and a more distensible pulmonary circulation [4], which is in keeping with the notion that a greater pulmonary vascular reserve allows for a higher aerobic exercise capacity, and vice-versa. On the opposite, ageing is associated with a progressive deterioration of the structure and function of the pulmonary

\footnotetext{
* Correspondence: christophe.delclaux@egp.aphp.fr

${ }^{1}$ AP-HP, Hôpital européen Georges-Pompidou, Service de Physiologie -

Clinique de la Dyspnée, 75015 Paris, France

${ }^{4}$ Sorbonne Paris Cité, Faculté de médecine, Université Paris Descartes, 75006

Paris, France

Full list of author information is available at the end of the article
}

vascular bed [5,6]. Using normative equations, one can calculate that VC would be zero around 100 years [7].

\section{Methods}

We thus enrolled both inactive and active (endurancetrained) healthy men to evaluate whether physical activity and age were correlated with $\mathrm{VC}$ at rest and with the increase in lung diffusion of $\mathrm{CO}\left(\mathrm{DL}_{\mathrm{CO}}\right)$ on exercise. Physical activity was evaluated using the French version of the International Physical Activity Questionnaire (IPAQ, long form) [8] that evaluates vigorous, moderate and walking activity domains. The resting $\mathrm{VC}$ was calculated using $\mathrm{DL}_{\mathrm{CO}}$ and lung diffusion of $\mathrm{NO}\left(\mathrm{DL}_{\mathrm{NO}}\right)$ measured simultaneously by the single-breath technique (4 seconds breath-hold, corrected for haemoglobin, assuming negligible erythrocyte resistance to NO [9], using an automatic apparatus (MasterScreenBody, Jaeger), as previously described [10]). VC measurements were also obtained at two levels of exercise (warm-up period and at $50 \%$ of the maximal work rate: see Figure 1, experimental protocol) to calculate the slope of the $\mathrm{DL}_{\mathrm{CO}} /$ work relationship as an index evaluating the dynamic capillary blood volume recruitment/dilation on exercise. The linearity of the relationship between power and $\mathrm{DL}_{\mathrm{CO}}$ has been demonstrated for $\dot{V}_{2} \leq 60 \%$ of $\dot{V} \mathrm{O}_{2, \text { peak }}$ 


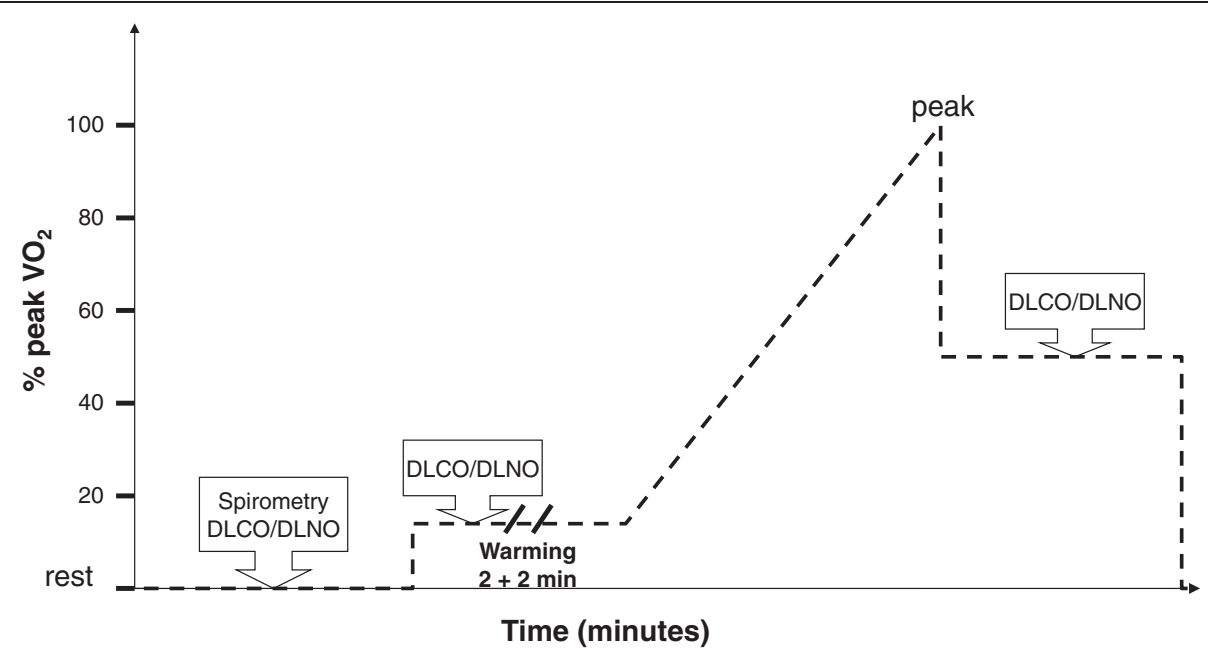

Figure 1 Description of the investigations (experimental protocol). Symptom-limited incremental exercise testing was conducted on an electronically braked cycle ergometer using the Vmax Cardiopulmonary Exercise Testing System (Sensor Medics, Yorba Linda, CA). After a 2 min warm-up period (inactive: 30 watts; trained subjects: 50 watts, corresponding to $\sim 15 \%$ of $\dot{V} \mathrm{O}_{2, \text { peak }}$ ), the workload was increased by $15-30$ Watts/ minute using a ramp protocol until exhaustion. The single breath $D L_{C O} / D L_{N O}$ measurements were obtained at rest and at two levels of exercise (a first warm-up period was performed before the ramp exercise test, and at $50 \%$ of the maximal work rate, immediately after peak exercise acquisition).

Table 1 Characteristics of the healthy men

\begin{tabular}{|c|c|c|c|c|}
\hline Characteristics $\mathrm{n}$ median [interquartile] & Healthy men $n=63$ & Inactive men $\mathrm{n}=31$ & Trained men $\mathrm{n}=32$ & $P$ value \# \\
\hline Age, years & $38[27 ; 47]$ & $37[29 ; 48]$ & $39[25 ; 46]$ & 0.574 \\
\hline Height, $\mathrm{cm}$ & $179[173 ; 185]$ & $177[171 ; 183]$ & $180[178 ; 186]$ & 0.038 \\
\hline Haemoglobin, g/dL & $14.4[13.7 ; 15.0]$ & $14.4[13.7 ; 15.4]$ & $14.3[13.7 ; 14.5]$ & 0.397 \\
\hline \multicolumn{5}{|l|}{ Physical activity assessment } \\
\hline Sport practice, hours/week & $4.0[0.0 ; 8.0]$ & $0.0[0.0 ; 0.0]$ & $7.0[5.0 ; 10.0]$ & $<0.001$ \\
\hline Vigorous-intensity domain, MET-min/week & $1200[0 ; 3840]$ & $0[0 ; 80]$ & $3840[2880 ; 6300]$ & $<0.001$ \\
\hline Total IPAQ score, MET-min/week & $3577[1105 ; 7482]$ & $1099[684 ; 2739]$ & $6943[3909 ; 9887]$ & $<0.001$ \\
\hline \multicolumn{5}{|l|}{ Resting values } \\
\hline $\mathrm{FEV}_{1}, \%$ predicted & $111[103 ; 119]$ & $108[99 ; 116]$ & $113[105 ; 122]$ & 0.137 \\
\hline $\mathrm{DL}_{\mathrm{CO}}, \mathrm{mmol} / \mathrm{min} / \mathrm{kPa}$ & $10.84[9.52 ; 11.68]$ & $10.51[8.55 ; 11.19]$ & $11.29[10.21 ; 12.08]$ & 0.005 \\
\hline $\mathrm{VC}, \mathrm{mL}$ & $95[82 ; 104]$ & $89[76 ; 99]$ & $103[89 ; 112]$ & 0.002 \\
\hline $\mathrm{DM}_{\mathrm{CO}}, \mathrm{mmol} / \mathrm{min} / \mathrm{kPa}$ & $22.53[21.51 ; 23.64]$ & 21.31 [19.80; 22.81] & $23.69[21.18 ; 25.67]$ & 0.019 \\
\hline \multicolumn{5}{|l|}{ At $50 \%$ peak work load } \\
\hline $\mathrm{DL}_{\mathrm{CO}}, \mathrm{mmol} / \mathrm{min} / \mathrm{kPa}$ & $13.42[12.81 ; 14.05]$ & 11.90 [10.67; 13.45] & 14.23 [13.08; 16.08] & 0.001 \\
\hline $\mathrm{VC}, \mathrm{mL}$ & $125[117 ; 132]$ & $108[95 ; 126]$ & $129[110 ; 153]$ & 0.025 \\
\hline $\mathrm{DM}_{\mathrm{CO}}, \mathrm{mmol} / \mathrm{min} / \mathrm{kPa}$ & $25.42[24.31 ; 26.44]$ & 23.41 [21.90; 24.92] & $27.33[25.81 ; 28.84]$ & $<0.001$ \\
\hline \multicolumn{5}{|l|}{ At peak exercise } \\
\hline Exercise duration, min & $640[589 ; 721]$ & $640[592 ; 735]$ & $632[585 ; 688]$ & 0.640 \\
\hline$\dot{\mathrm{V}} \mathrm{O}_{2}, \mathrm{~mL} / \mathrm{kg} / \mathrm{min}$ & $2932[2370 ; 3600]$ & $2385[2068 ; 2671]$ & 3468 [3181; 3900] & $<0.001$ \\
\hline$\dot{\mathrm{V}} \mathrm{O}_{2}, \%$ predicted & $95[80 ; 108]$ & $80[68 ; 93]$ & $107[97 ; 119]$ & $<0.001$ \\
\hline
\end{tabular}

\#using Mann and Whitney $U$ test.

VC denotes capillary blood volume and $\mathrm{DM}_{\mathrm{CO}}$ denotes the pulmonary membrane diffusing capacity for carbon monoxide calculated using single breath $\mathrm{DL}_{\mathrm{CO}} / \mathrm{DL}_{\mathrm{NO}}$ measurement. 
Table 2 Univariate analyses assessing the factors associated with resting capillary blood volume and slope of $\mathrm{DL}_{\mathrm{co}} /$ work relationship

\begin{tabular}{|c|c|c|c|c|}
\hline \multirow[b]{2}{*}{ Linear regression, pearson } & \multicolumn{2}{|c|}{ Resting capillary blood volume, $\mathrm{mL}$} & \multicolumn{2}{|c|}{ Slope of $\mathrm{DL}_{\mathrm{co}} /$ work relationship, $\mathrm{mmol} / \mathrm{min} / \mathrm{kPa} / \%$ peak work rate } \\
\hline & $r$ value & $P$ value & r value & $P$ value \\
\hline Age, years & -0.545 & $<0.001$ & -0.258 & 0.041 \\
\hline Height, cm & 0.537 & $<0.001$ & 0.324 & 0.009 \\
\hline Peak $\dot{V} \mathrm{O}_{2}, \mathrm{~mL} / \mathrm{kg} / \mathrm{min}$ & $0.390 \#$ & 0.002 & 0.244 & 0.045 \\
\hline Sport practice, hours/week* & 0.360 & 0.006 & 0.278 & 0.034 \\
\hline Vigorous-IPAQ, MET-min/week & 0.356 & 0.004 & 0.264 & 0.036 \\
\hline Total-IPAQ, MET-min/week & 0.116 & 0.364 & 0.218 & 0.086 \\
\hline
\end{tabular}

*sports were rowing $(=19)$ triathlon $(n=6)$ and miscellaneous $(n=7)$ for the 32 endurance-trained men. The Vigorous-IPAQ domain was clearly related to sport practice duration $\left(r^{2}=0.64 ; p<0.0001\right)$.

\#: the Pearson coefficient increased to 0.53 after excluding the two outliers using the Tietjen and Moore method (that is consistent with the $r$ value of 0.60 for the same relationship in the study of Lalande et al. [4]).

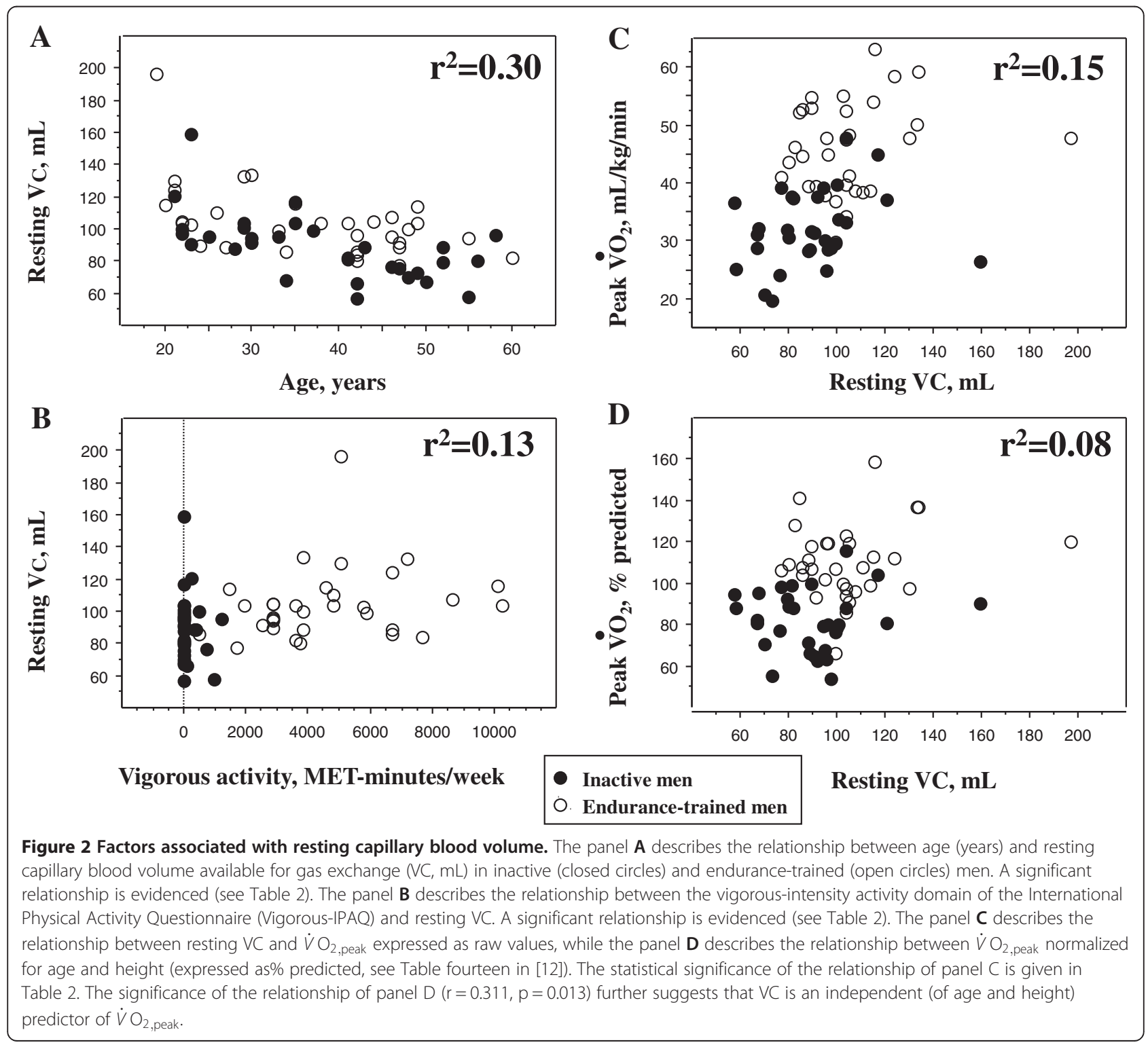


[11]. Symptom-limited incremental exercise testing was conducted on an electronically braked cycle ergometer according to the recommended guidelines [12], as previously described [13] using a 2 min warm-up period followed by a ramp protocol (see Figure 1 legend) until exhaustion. Spirometry was obtained before exercise.

\section{Results}

A total of 64 healthy (no medication, never smokers or ex-smokers $<5$ pack-year, no history of asthma, between 40 and 60 years of age) Caucasian men were recruited: 32 inactive subjects (not meeting specified American physical activity guidelines of at least 1 hour and 15 minutes a week of vigorous-intensity aerobic physical activity, for five consecutive years) and 32 endurancetrained subjects (sport practice $>3$ hours/week for 5 consecutive years). One inactive man was unable to perform apneas for $\mathrm{DL}_{\mathrm{CO}}$ measurements and was excluded. Informed written consent was obtained from all subjects, and ethical approval (CPP IDF VI, ID-RCB: 2011A00006-35) was received.

The main characteristics of the healthy men at rest and on exercise are described in Table 1 while univariate analyses of factors associated with the quantity and quality indices of pulmonary vascular bed are described in Table 2 and Figure 2. Multivariate analyses (age, height and activity as independent variables) demonstrated that both age and vigorous-intensity activity domain remained independent predictors of resting VC $\left(\mathrm{R}^{2}=0.37\right.$, $\mathrm{p}$-value (vigorous intensity activity) $=0.0123$, p-value (age) $<0.001$ ), and of the slope of $\mathrm{DL}_{\mathrm{CO}}$ increase $\left(\mathrm{R}^{2}=0.25\right)$.

\section{Discussion}

Lalande et al. recently demonstrated that $\dot{V} \mathrm{O}_{2 \text {,peak }}$ is associated with a greater $\mathrm{VC}$ and with a more distensible pulmonary circulation [4] that deserved to be confirmed. We enrolled a larger sample of healthy subjects with a wide range of physical activity levels allowing to establish the relationship between physical activity and $\dot{V}$ $\mathrm{O}_{2 \text {,peak }}$ and to perform a multivariate analysis more confidently. Different methods for VC measurement have been used with and without inhaled NO; their agreement is satisfactory [14]. The degree of both $\mathrm{DL}_{\mathrm{CO}}$ and VC increase during exercise ( 20-25\%) in our study was similar with that described by Lalande et al. [4]. Overall, the level of statistical significance of the correlations evidenced is weak to moderate. Several factors may explain this finding such as genetic heritability and inherent limitations due to indirect measures of vascular indices (with two outliers, see Figure 1). The genetic heritability of $\dot{V} \mathrm{O}_{2, \text { peak }}$ is around 50\% [15], which may explain the overlap between $\dot{V} \mathrm{O}_{2 \text {,peak }}$ is evidenced in inactive and trained men in our study, and further justify the weak relationship between physical activity and vascular indices.

The results of this cross-sectional study rely on correlations that do not make causality. Nevertheless, one may hypothesize that endurance sport practice favours lung growth and capillary blood volume increase as observed for lung volumes $[16,17]$.

In conclusion, our cross-sectional study suggests that, in healthy men aged 20 to 60 years, endurance sport practice is associated with better quantity and quality of the pulmonary vascular bed, partly counterbalancing the deleterious effects of ageing, which remains to be demonstrated in a prospective longitudinal design.

\section{Abbreviations}

VC: capillary blood volume available for gas exchange; CO: carbon monoxide; NO: nitric oxide; $\dot{V} \mathrm{O}_{2}$ : peak, peak oxygen consumption; $\mathrm{DL}_{\mathrm{Co}}$ : lung diffusion of CO; IPAQm: International Physical Activity Questionnaire; $\mathrm{DL}_{\mathrm{NO}}$ : lung diffusion of $\mathrm{NO}$.

\section{Competing interests}

All the authors declare that they have no competing interests.

\section{Authors' contribution}

All the authors made substantial contributions to conception and design (JFT, FDD, CD2), or acquisition of data (GAD, CL, LP, BCB), or analysis and interpretation of data (ACP); drafted the submitted article or revised it critically for important intellectual content (all authors); and provided final approval of the version to be published (all authors).

\section{Acknowledgments}

The authors wish to thank the technicians of the pulmonary function laboratory for their expert assistance (Martine Riquelme, Françoise Genisty, Mireille Morot, Marien Bokouabassa), the different contributors from the Unité de Recherche Clinique of the Hôpital Européen Georges Pompidou (Gilles Chatellier [medical coordinator], Noël Lucas [medical coordinator], Yann Guivarch [financial account manager], Chantal Andrieux [clinical trial coordinator] and Kévin Masini [data manager]), the Centre d'Investigations Cliniques (recruitment of healthy subjects, Dr. Anne Blanchard and Prof Michel Azizi, director) and the Direction de la Recherche Clinique et du Développement (DRCD of AP-HP: Damien Vanhoye) for sponsoring. Christophe Delclaux takes responsibility for the content of the manuscript.

\section{Funding}

This study was funded by a grant from the Assistance Publique - Hôpitaux de Paris (AP-HP : Direction de la Recherche Clinique et du Développement). The Unité de Recherche Clinique was responsible for independent data monitoring and analysis (Aurore Caumont-Prim) under the supervision of our sponsor (Assistance Publique - Hôpitaux de Paris; project code: P101102, SAINVAPU study). The sponsor had no role in study design, in the collection, analysis and interpretation of data, in the writing of the report and in the decision to submit the article for publication.

\section{Author details}

${ }^{1}$ AP-HP, Hôpital européen Georges-Pompidou, Service de Physiologie Clinique de la Dyspnée, 75015 Paris, France. ${ }^{2}$ AP-HP, Hôpital européen Georges-Pompidou, Unité d'Épidémiologie et de Recherche Clinique, 75015 Paris, France. ${ }^{3}$ Institut de Recherche bioMédicale et d'Epidémiologie du Sport, INSEP, Paris, France. ${ }^{4}$ Sorbonne Paris Cité, Faculté de médecine, Université Paris Descartes, 75006 Paris, France. ${ }^{5}$ Université Paris Descartes, Sorbonne Paris Cité, EA2511, 75014 Paris, France. ${ }^{6} \mathrm{CIC} 9201$ Plurithématique, Hôpital Européen Georges Pompidou, 75015 Paris, France. ${ }^{7}$ Physiologie Respiratoire - Clinique de la Dyspnée, Hôpital européen Georges-Pompidou, 20, rue Leblanc, 75015 Paris, France.

Received: 5 December 2013 Accepted: 23 January 2014

Published: 24 January 2014 
References

1. Argiento P, Chesler N, Mule M, D'Alto M, Bossone E, Unger P, Naeije R: Exercise stress echocardiography for the study of the pulmonary circulation. Eur Respir J 2010, 35(6):1273-1278.

2. Reeves JT, Linehan JH, Stenmark KR: Distensibility of the normal human lung circulation during exercise. Am J Physiol Lung Cell Mol Physiol 2005, 288(3):L419-L425.

3. Roughton FJ, Forster RE: Relative importance of diffusion and chemical reaction rates in determining rate of exchange of gases in the human lung, with special reference to true diffusing capacity of pulmonary membrane and volume of blood in the lung capillaries. $J$ Appl Physiol 1957, 11(2):290-302.

4. Lalande S, Yerly P, Faoro V, Naeije R: Pulmonary vascular distensibility predicts aerobic capacity in healthy individuals. J Physio/ 2012, 590(Pt 17):4279-4288.

5. Argiento P, Vanderpool RR, Mule M, Russo MG, D'Alto M, Bossone $E$, Chesler NC, Naeije R: Exercise stress echocardiography of the pulmonary circulation: limits of normal and sex differences. Chest 2012, 142(5):1158-1165.

6. Janssens JP, Pache JC, Nicod LP: Physiological changes in respiratory function associated with ageing. Eur Respir J 1999, 13(1):197-205.

7. Aguilaniu B, Maitre J, Glenet S, Gegout-Petit A, Guenard H: European reference equations for CO and NO lung transfer. Eur Respir J 2008, 31(5):1091-1097.

8. Macfarlane DJ, Lee CC, Ho EY, Chan KL, Chan D: Convergent validity of six methods to assess physical activity in daily life. J App/ Physiol 2006, 101(5):1328-1334.

9. Guenard H, Varene N, Vaida P: Determination of lung capillary blood volume and membrane diffusing capacity in man by the measurements of NO and CO transfer. Respir Physiol 1987, 70(1):113-120.

10. Londner C, Al Dandachi G, Plantier L, Gillet-Juvin K, Chevalier-Bidaud B, Mahut B, Israel-Biet D, Delclaux C: Cross-sectional assessment of the relationships between dyspnea domains and lung function in diffuse parenchymal lung disease. Respiration 2013. Epub ahead of print.

11. Kinker JR, Haffor AS, Stephan M, Clanton TL: Kinetics of CO uptake and diffusing capacity in transition from rest to steady-state exercise. J Appl Physiol 1992, 72(5):1764-1772

12. Anonymous: ATS/ACCP Statement on cardiopulmonary exercise testing Am J Respir Crit Care Med 2003, 167(2):211-277.

13. Delclaux C, Chevalier-Bidaud B, Essalhi M, Callens E, Graba S, Gillet-Juvin K, Valcke-Brossollet J, Mahut B: Too rapid increase and too much breathlessness are distinct indices of exertional dyspnea in COPD. Respir Physiol Neurobiol 2011, 176(1-2):32-38.

14. Tamhane RM, Johnson RL Jr, Hsia CC: Pulmonary membrane diffusing capacity and capillary blood volume measured during exercise from nitric oxide uptake. Chest 2001, 120(6):1850-1856.

15. Bouchard C, Daw EW, Rice T, Perusse L, Gagnon J, Province MA, Leon AS, Rao DC, Skinner JS, Wilmore JH: Familial resemblance for VO2max in the sedentary state: the HERITAGE family study. Med Sci Sports Exerc 1998, 30(2):252-258

16. Doherty M, Dimitriou L: Comparison of lung volume in Greek swimmers, land based athletes, and sedentary controls using allometric scaling. $\mathrm{Br}$ J Sports Med 1997, 31(4):337-341.

17. Silvestri M, Crimi E, Oliva S, Senarega D, Tosca MA, Rossi GA, Brusasco V: Pulmonary function and airway responsiveness in young competitive swimmers. Pediatr Pulmonol 2013, 48(1):74-80.

doi:10.1186/1465-9921-15-8

Cite this article as: Al Dandachi et al:: Ageing and endurance training effects on quantity and quality of pulmonary vascular bed in healthy men. Respiratory Research 2014 15:8.

\section{Submit your next manuscript to BioMed Central and take full advantage of:}

- Convenient online submission

- Thorough peer review

- No space constraints or color figure charges

- Immediate publication on acceptance

- Inclusion in PubMed, CAS, Scopus and Google Scholar

- Research which is freely available for redistribution

Submit your manuscript at www.biomedcentral.com/submit
C Biomed Central 